\title{
Imágenes encontradas de una guerra. Un acercamiento al "Libro Bellamente Ilustrado" del siglo XIX Mexicano
}

\author{
Edgar A. G. EncINA \\ Universidad Autónoma de Zacatecas \\ Universidad Complutense de Madrid \\ lipofima@hotmail.com
}

\begin{abstract}
RESUMEN
Las siguientes líneas habrán de pretextar The war between the United States and México de Karl Nebel. Un «libro bellamente ilustrado» inspirado en la intervención norteamericana en tierras mexicas entre los años de 1846 y 1848 , que desde sus propios objetivos y voluntades formula varias miradas, algunas aventuradas. En ese sentido, se exploran los motivos socio-políticos del evento pero, por principio, se revisa la obra como paratexto, sus recepciones y lecturas, deliberando -desde el inicio- que la imagen en una edición también escribe lenguajes internos y externos, complejos y apabullantes.

El presente ensayo pretexta algunos de los aportes del varón Humboldt en materia impresa y, a su vez, la aportación e influencia que tuvo en la labor de los "Artistas viajeros" que recorrieron México a lo largo del siglo XIX. Este pretexto es para contextualizar y situar The war between the United States and México de Karl Nebel, una obra nodal para ambos países en materia de los libros bellamente ilustrados. Pero, ¿cómo conviven la pintura y la literatura en un mismo espacio? Al parecer, lo hacen siempre en constante forcejeo que, según la obra, el artista y el escritor, se ve favorecida una u otra. En este caso, la imagen es la reina que demanda apenas de la literatura para subrayar su discurso y, a su vez, simboliza el papel de la imagen que puede analizarse, estudiarse e interpretarse, igual que otra categoría.
\end{abstract}

Palabras clave: artistas viajeros en el México del siglo XIX; Libro Bellamente Ilustrado; pintura; literatura.

\section{Opposed Images on Behalf of the War. An approach to the "Beautifully Illustrated Book" in the 19th Century in México}

\begin{abstract}
The following lines will analyse The War between the United States and Mexico Karl Nebel, a "beautifully illustrated book" inspired in the American intervention in Mexican territory between 1846 and 1848, that, with its own goals and desires, offers several points of view, some of them adventurous. In that sense, we will explore the socio-political reasons, although the book is basically reviewed as a paratext, its receptions and lectures, deliberating -from the start- that the image in an edition also writes internal as well as external languages (complex and overwhelming).

The present essay pretexts some of the contributions of male Humboldt in printed matter as well as the contribution and influence it had on the work of "community artists" who toured Mexico during the 19th century. This pretext aims to contextualize and situate The War between the United States and Mexico of Karl Nebel, as nodal work for both countries in beautifully illustrated books. But how do painting
\end{abstract}


and literature coexist in the same space? Apparently, they always do it in constant struggle, according to the work, the artist and writer, are favourable to each other. In this case, the image is just the queen who demands literature to underscore her speech, at the same time that it symbolises the role of the image that can be analysed, studied and interpreted, just as other categories.

Key words: traveling artist in the 19th century México; Beautifully Illustrated Book; painting; literature.

Alexander von Humboldt (Alemania; 1769-1859) visitó y exploró entre 1803 y 1804 México, entrando por Acapulco viniendo de Guayaquil, Ecuador. La prueba del viaje está en el detallado Ensayo político sobre el reino de la Nueva España ${ }^{1}$, publicado en 1810, para Carlos IV, título que sucediera el Viaje a las regiones equinocciales del Nuevo Continente y fuera antecedente del Atlas geográfico. Según Jaime Labastida, algunas de las obras del alemán fueron publicadas, primero, como pliegos y, después, en volúmenes, por ello las fechas originales de difusión, en algunos casos, abarcan el año en adelante. Sumado, Ensayo político contiene diferente número de mapas según el tomo ${ }^{2}$; Viaje a las regiones ${ }^{3}$ al parecer fue editado en múltiples volúmenes, con gráficos trazados; Atlas geográfico comprende veinte láminas, de las cuales dieciséis fueron dibujadas y/o corregidas por el autor ${ }^{4}$.

El barón Humboldt con este y otro buen número de obras, por un lado, fascinó un nutrido grupo de europeos con la idea de "las Américas". Consciente o no, su labor de promoción trajo el establecimiento de migrantes con un examen novedoso; no de

1 La traducción más antigua que conozco de los tres tomos del Ensayo politico sobre el reino de la Nueva España (Essai politique sur le royaume de la Nouvelle Espagne) es de don Vicente González Arnao, fechado en la ciudad de París, en "casa de Rosa, Gran Patio del Palacio Real, y calle de Montpensier, no. 5", de 1822. Es probable que la fuente original sea Essai politique sur le Royaume de la Nouvelle Espagne, Schoell, Paris, 1808-1811 y Relation historique du Voyage aux régions équinoxiales du Nouveau Continent, volumen III, Smith et Gide, Paris, 1825. En 1973 la editorial Porrúa hizo una edición del Ensayo y en 2004 aparece en su colección Sepan cuántos ..., número 39, con el estudio de Juan A. Ortega y Medina.

2 LABASTIDA, Jaime, "Humboldt en la Nueva España", en Culture and Society in the New World, City University of New York, The Graduate Center, 2012, pp. 25-39.

3 Viaje a las regiones equinocciales del Nuevo Continente (Voyage aux régions equioxiales du Nouveau Contintent) fue escrita entre los años de 1799 y 1804, pero publicada en 1807 por Aimé Bonpland (Francia; 1773-1858). Dice el tomo primero que fue trabajado en la Imprenta Pochard, en casa de Rosa, París, de 1826. En 1997 la editorial Siglo XXI hizo una reedición de la obra, la cual parece agotada. El libro es considerado una de las referencias históricas fundamentales en el estudio de la geografía.

4 Atlas geográfico fue publicado por vez primera en 1811. La edición de 2003, de la editorial Siglo XXI, de 148 páginas, afirma que todos los grabados se apegaron rigurosamente a las instrucciones del autor a partir de una descripción realizada en la "Introducción geográfica". Se trata de un texto que no conozco físicamente. Las referencias que tengo son de segunda o tercera mano porque me le he acercado a través fragmentos de ediciones escaneadas que circula en la red e información cruzada. Sin embargo, el acercamiento es incompleto, pues no he localizado una descripción técnica del libro y, sobre todo, de las imágenes. Por ejemplo, falta decir en qué tipo de papel se imprime, qué tintas se usaron, quiénes fueron los responsables en la prensa, dónde fueron trabajadas las imágenes y si hubo modelos dibujados o solo descripciones escritas, por citar algunos detalles. Atlas geográfico y físico de la Nueva España, escribe José Herrera Peña en La Biblioteca de un Reformador (México, Universidad Michoacana de San Nicolás de Hidalgo, 2005, p. 39), que fue publicado en México en 1844 y del cual, se asevera, existen algunos errores con los trazos de varios ríos. 


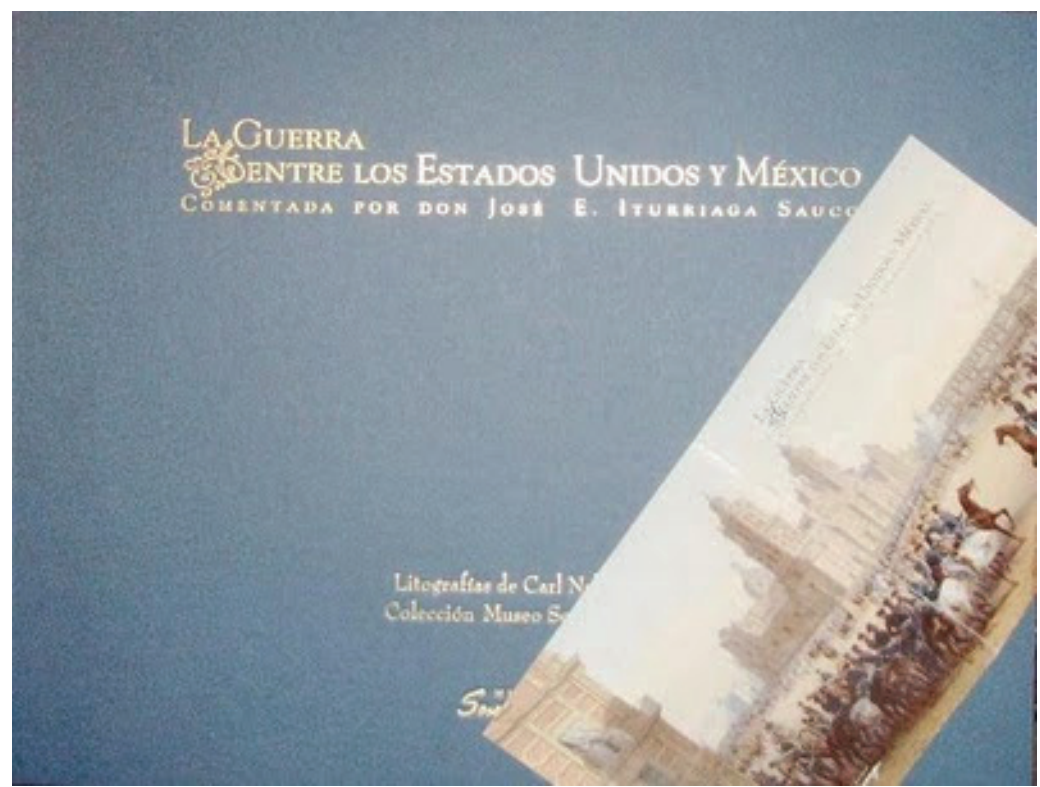

Fig. 1. Imagen del libro-carpeta The war between the United States and México de Karl Nebel.

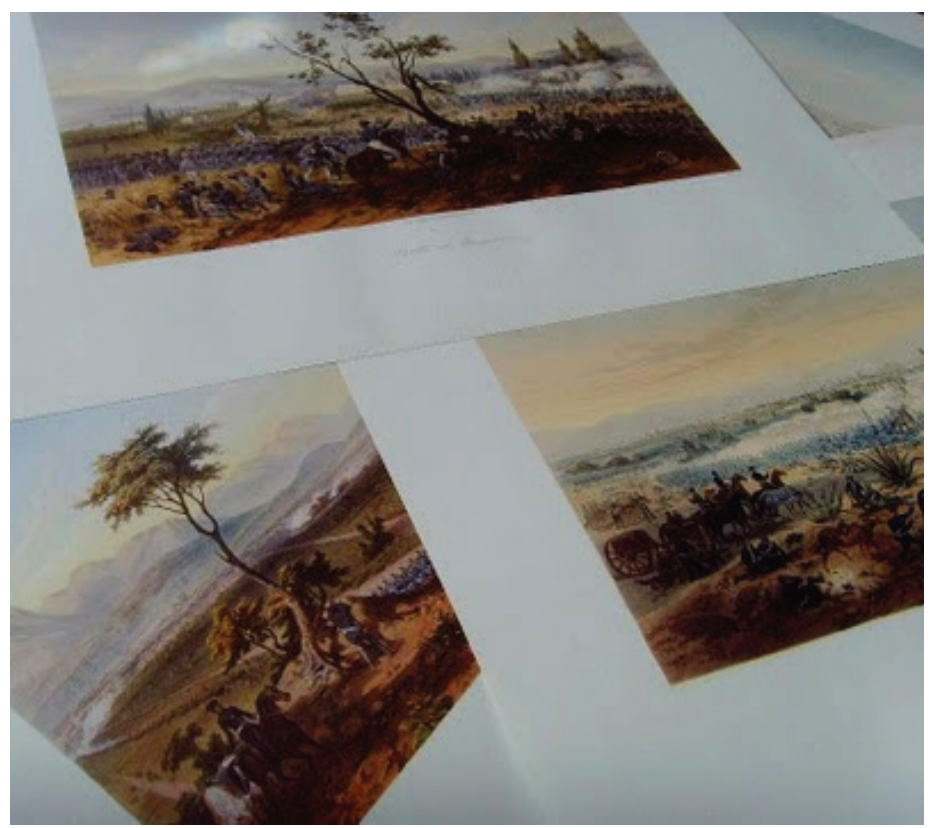

Fig. 2. Imagen del libro-carpeta The war between the United States and México de Karl Nebel. 
afanes colonialistas, en todo caso más con una actitud lúdica, artística, cultural ${ }^{5}$. Por otro lado, a manera de rebote, produjo que un buen número de esos extranjeros escribiera y pintara sobre sus viajes, resultando tintas con afanes ilustrados; su intención fue enciclopédica, de registro científico, casi catastral ${ }^{6}$. De ello, cuajó una forma de hacer-entender el Romanticismo que contrasta con el otro Romanticismo, ese que explora para reproducir-crear privilegiando las experiencias emotivas, los apegos subjetivos y el rescate de la tradición empirista-naturalista?

Un tercer argumento se suma a la fascinación-actitud lúdica-artística-cultural y a las diferentes maneras de hacer-entender el Romanticismo. La producción del alemán -aquí me arriesgo, amén de cuajar una fría hipótesis- deja un precedente expresivo, por llamarle de alguna forma, al menos para los decimonónicos. Su trabajo no consistió solo en la redacción de hechos, también combinó el ejercicio imaginario. Ejemplo de esto, diversos títulos combinan la presencia de dibujos, láminas, trazados y/o grabados con los textos escritos, soportando-conformando ideas más expresivas e imaginarias. Uno de los ejemplos mejor acabados es el Atlas geográfico, porque a pesar de que Humboldt no era un artista gráfico - propiamente descrito- sí adoctrinó a sus editores y colaboradores en la confección precisa de las imágenes que deseaba proyectar, preocupándose por los acabados y detalles finales.

Si bien Atlas geográfico u otras ediciones han sido encasillados por distintas ramas del conocimiento, en su caso la geología, de la misma manera debe atenderse su revisión con un examen diverso, ya que su aporte es puntual -a su vez- para las artes, la cultura y el universo de las ideas. Innegable es el aporte cientificista que retrata en talante de mapas imágenes de América. Sin embargo, la calidad expresiva y de realizado están ahí y no deben obviarse ni pasarse por alto. La iconografía, a nuestra mirada, labra una condición de atractivo, un toque especial -siendo románticos-que alegra la vista moderna. No es que las láminas deban catalogarse como arte, pero sí pueden entenderse como una forma motivante, un antecedente quizá, un ejemplo o idea naciente que algunos de sus contemporáneos habrán de tomar para cristalizar, para moldear proposiciones incorporando palabra a la imagen o imagen a la palabra.

Aquellos forasteros allegados a México en el siglo XIX, fascinados por la idea humboldteana de trajinar, asentar y crear; de embeberse, escrutar, seducirse y de desnudar las nuevas tierras terminaron por legarnos testimonios cruciales para el registro de nuestra historia que, además, tienen un gran valor estético ${ }^{8}$. Uno de ellos Carl Nebel (Alemania; 1805-1855) produjo La guerra entre los Estados Unidos y México ${ }^{9}$, en los años de 1847 a 1855 . Me detendré en este autor y la obra. El trabajo

5 TIBON, Gutierre, Historia del nombre y de la fundación de México, México, F.C.E., 1975. VV.AA., Materia y sentido. El arte mexicano en la mirada de Octavio Paz, México, MuNal-Océano, 2009.

6 AGUILAR OCHOA, Arturo, "Aventura visual de un pintor viajero", en Artes de México, n 80, agosto de 2006 , p. 3.

7 Ibid., pp. 10-14.

8 Artes de México, no 31 (número dedicado a El viajero europeo del siglo XIX), junio de 2004.

9 La guerra entre los Estados Unidos y México (The war between the United States and México) es una fina obra publicada por el Museo Soumaya, con "[...] motivo de [los] ciento sesenta años de la batalla de 
es una colección-carpeta-libro; contiene doce litografías con gouache y acuarela que enmarcan distintas batallas, ataques, tomas y entradas por el ejército estadounidense a ciudades, sitios y ubicaciones mexicanas ${ }^{10}$. Justino Fernández afirma que la edición aparece, primero, en Nueva York, en 1851 con 10 láminas, luego en París, para sumar otras impresiones ${ }^{11}$, y asevera que:

Buena Vista ([del] 22 de febrero de 1847)", escribe el curador Héctor Palhares Meza. La elegante edición, comentada por José E. Iturriaga Sauco (México; 1912-2011) e ilustrada por Carl Nebel (Alemania; 18051855), formó, en su momento, un selecto adelanto a los festejos del bicentenario independentista. NEBEL, Carl (litografías) e ITURRIAGA SAUCO, José E. (comentarios), La Guerra entre los Estados Unidos y México, México, Fundación Carso, colección Museo Soumaya, 2006. Además de The war between the United States and México de Nebel, existen otras ediciones que escribieron, pensaron e imaginaron el conflicto. Está el Army Portfolio del capitán Daniel Powers Whiting (EE.UU.; 1808-1892), en 1847; el Naval Portfolio, de 1848, por el teniente de navío Henry Walke (EE.UU.; 1809-1896); o México Illustrated in Twenty Six Views, del mismo año, por John Phillips y Alfred Rider. Sumado, están los dos tomos de los Recuerdos de la invasión norteamericana (1846-1848) por un joven de entonces, de José María Roa Bárcena (México; 1827-1908); La intervención norteamericana 1846-1848, de Josefina Zoraida Vázquez; La entrada de las tropas estadounidenses a la ciudad de México: la mirada de Carl Nebel, de Fabiola García Rubio, entre una nutrida lista. El conflicto presenta dos miradas sensibles para ambos países; cada cual con su lectura. Uno, Estados Unidos, se ufana del primer triunfo, luego de constituirse país, en una guerra fuera de su territorio. El segundo, México llora la derrota con sus dolorosas consecuencias. Súmese a ello que estas líneas tienen la intención, pretextando The War between the United States and México de Carl Nebel, de presentar un bosquejo histórico y sensible de lo que llevó la edición de un libro de arte y los avatares por los que debió naufragar para sostenerse. Se hizo necesario, por cuestiones de tiempo-espacio, rodear brevemente al texto, comentar otras labores del autor, señalar los cómo, determinar los dónde; se obvio cercar al tema de la litografía, su llegada al país, los precursores del arte, los colofones maquinados, sus derivados, su aportación al tema de las publicaciones en general. Además, dejaron de nombrarse más de una treintena de libros de arte, lo cual dice más de lo que calla. Sin embargo, la idea central fue sembrar una vista general sobre el libro de arte en el México decimonónico. Falta aún mucho que escribir, no solo del plano histórico, también del artístico, del literario, del estético; ya otras hojas tratarán de remediar el asunto. Por cierto, el "chelín" fue una moneda de plata fraccionaria en Inglaterra. Desapareció cuando el sistema monetario del país fue reducido al sistema decimal, en 1971. En su tiempo, el chelín tenía 12 peniques, la libra 20 chelines; fue la vigésima parte de la libra esterlina. Entiendo que en algunos países africanos y en Australia la moneda continúa en circulación. Existe un hermoso cuento de Hans Cristian Adersen (Dinamarca; 1805-1875) titulado "El chelín de plata" que inicia así: "Érase [sic] una vez un chelín. Cuando salió de la ceca, pegó un salto y gritó, con su sonido metálico “¡Hurra! ¡Me voy a correr el mundo!” Y, efectivamente, este era su destino”.

10 Las litografías enmarcan las batallas de Palo Alto en Tamaulipas (Battle of Palo Alto), de Buena Vista en Monterrey, Nuevo León (Battle of Buena Vista), del Cerro Gordo (Battle of Cerro Gordo), de Contreras (Battle of Contreras, Assault of Contreras, inscripción manuscrita), de Churubusco (Battle of Churubusco), del Molino del Rey (Battle of El Molino del Rey) con los ataques al Molino del Rey (Attack upon The Molino) y a la Casa Mata (Attack upon the Casa Mata), El asalto de Chapultepec (The Storming of Chapultepec) con los ataques de Pillow (Pillow's Attack) y de Quitman (Quitman's Attack), las tomas de Monterrey (The Capture of Monterrey) y de Veracruz (The Capture of Veracruz y/o Bombardment of Veracruz, inscripción manuscrita) y la entrada del general Scott en México (General Scott's Entrance into Mexico). Para el detalle cabe aludir las inscripciones "Boyot lith", al centro, "dado de alta de acuerdo al acto del Congreso" ("Entered according to act of Congress"), a la derecha o izquierda indistintamente rubricados por su autor, "C. Nebel fecit", e impresos por Lemercier, en París, Francia. Fecit es un vocablo latino, puede trasladarse como "hizo". Es común que aparezca esta inscripción justo después del nombre del autor para autentificar el trabajo. Las variaciones de la "mancha" oscila entre los $28 \times 35 \mathrm{cms}$., $27.3 \times 42.7 \mathrm{cms}$., y $27.3 \times 43 \mathrm{cms}$., en un papel de $45 \times 60 \mathrm{cms}$. La "mancha" es el área de la imagen. Los textos se imprimen aparte, sobre papel. http://materiadetestamento.blogspot.com. es/2010/01/la-imagen-de-la-memoria-o-los-retratos.html

11 NEBEL, Carl, The war between the United States and México, New York, Appleton, 1851. 
[...] es indudable que Nebel no había presenciado tal guerra, ni menos las batallas que pinta, así, debe haber trabajado sobre apuntes de paisajes que llevó consigo en 1834 o, bien de otros suministrados por algún artista. En todo caso puede asegurarse que en buena parte es obra de imaginación, pero supo dar cierta verdad a sus visitas ${ }^{12}$.

Así, el testimonio manifiesta que la edición francesa fue elaborada para un consumo europeo y, tal vez, mexicano; que el autor pudo verla terminada, en circulación, al menos, sus dos primeras impresiones; que las cataduras realistas, las técnicas-formas de-en elaboración y los temas reconocidos-encontrados en sus planchas no denotan esa ausencia presencial en el conflicto, dando a bien la intención del creador e impresionando en la "veracidad" que acomete para el que las aprecia. Es significativo que la edición inaugural fuese norteamericana, con autorización del Congreso, y que los retratos del ejército norteamericano detenten, entre otras cosas, un preciso orden y una pulcritud en el uso de los uniformes.

Un breve paréntesis. La relación de Humboldt con Nebel va más allá de su procedencia germánica. En el Viaje pintoresco y arqueológico sobre la parte más interesante de la República Mexicana ${ }^{13}$ el primero afirmó ver en el trabajo del segundo la astucia de un arquitecto, más que la del diseñador, quizá porque se evidenciaban estudios bibliográficos y de formación en los aspectos reservados a su tiempo, como el dibujo ${ }^{14}$. La maestría, apunta el varón sobre Nebel, es notoria en las

[...] grandes vistas con paisaje [...] tratadas con sabiduría en la composición y con conocimiento directo en todos sus detalles. [...] No tiene rival cuando compone escenas costumbristas [...] o con fondos de arquitectura. La gracia y buen diseño de todas las imágenes $[\ldots]$ hacen muy atractivas sus litografías $[\ldots]^{15}$.

De vuelta a La Guerra... el museo Soumaya, "[c] on motivo de los ciento sesenta años de la batalla de Buena Vista [del] (22 de febrero de 1847)"16, la ha reeditado en preámbulo a los festejos independentistas, con un cuadernillo seriado por los comentarios de José E. Iturriaga Sauco (Ciudad de México; 1912-2011) ${ }^{17}$, un glosario y un cedulario técnicamente bien realizado ${ }^{18}$. Las elucidaciones de Iturriaga están elaboradas en relación al contexto histórico en el que se dan los sucesos; se planta en las ba-

\footnotetext{
12 FERNÁNDEZ, Justino, El arte del siglo XIX en México, México, UNAM-IIE, 1967, p. 34.

13 NEBEL, Carl, Viaje pintoresco y arqueológico sobre la parte más interesante de la República Mexicana, en los años transcurridos desde 1829 hasta 1834 (Voyage pittoresque et archéologique dans la partie la plus intéressante de Mexique), observaciones de Alejandro de Humboldt, prólogo de Justino Fernández, México, Edición facsimilar, Miguel Ángel Porrúa, 1963. No todos los trabajos fueron dibujados a color por Nebel.

14 FERNÁNDEZ, Justino (1967), op. cit., p. 34.

15 Ibid., pp. 34-35.

16 PALHARES MEZA, Héctor, "Una mirada romántica de la guerra entre México y los estados Unidos (1846-1848). Doce litografías de Carl Nebel”, en Folleto del Museo Soumaya, febrero 2007, pp. 4-6.

17 José Ezequiel Iturriaga y Sauco fue uno de los especialistas en el tema de la guerra entre los Estados Unidos y México, por ello el mérito de sus palabras y quizá la intención de que escribiera el cuadernillo que acompaña las litografías. Para soportar este argumento refiero las 391 páginas del libro Ustedes y nosotros, editado por la dirección General de Publicaciones de la UNAM, en 2006.

18 NEBEL, Carl e ITURRIAGA SAUCO, José E. (2006), op. cit.
} 
tallas y, al poco, hace descripciones que amparan el vistazo de la imagen. Para hacer notar las referencias en sus argumentos utiliza cursivas, y separa los párrafos entre sí con un espacio. Aunado, la redacción no contiene lenguaje complicado, ni denota términos especializados. En un sentido, el texto escrito acompaña al texto pictórico:

Las litografías que ilustran las batallas impuestas a México por los Estados Unidos de Norteamérica se comprenderán mejor si recordamos que nuestros vecinos apadrinaron a Moisés Austin [1761-1821] cuando pidió a la monarquía española -Fernando VII [1784-1833] a la cabeza- la entrada de 300 colonos para asentarse en torno a San Antonio de Béjart, en la Provincia de Coahuila y Texas de la Nueva España.

Para otorgar el permiso respectivo, el monarca español exigió a los presuntos colonos que solo siendo católicos, apostólicos, romanos, y observar además con puntualidad los ritos y prácticas de esa religión, podrían asentarse en esa parte norteña de la Nueva España.

Independizada esta de su Madre Patria en 1821 [...] Agustín de Iturbide [17831824] se convirtió en el emperador de México [...]

Sin tardanza alguna, Samuel Houston [1793-1863] y Esteban Austin [1793-1836] -hijo de Moisés- vinieron a entrevistarse [...] para revalidad los títulos de colonos [...] Iturbide les advirtió que podían seguir como colonos en la Provincia de Coahuila y Texas, siempre y cuando practicaran los ritos y la doctrina de la Iglesia católica, apostólica, romana. Éstos juraron que así lo harían, pero ningún funcionario mexicano verificó si cumplían o no con el requisito exigido.

\section{$[\ldots]$}

Entre tanto, en México se eligió un congreso constituyente que de 1823 a 1824, redactó uno a uno los artículos que contienen la Constitución de 1824, y en ella se estableció la República Federal de los Estados Unidos Mexicanos [...]

El primer presidente del México Autónomo [1824-1829] fue Guadalupe Victoria [1786-1843] y a él se acercaron los líderes de los colonos texanos para pedirle que no modificara su condición de colonos, dispuestos como estaban a observar los ritos y la doctrina de la Iglesia católica romana

Las pugnas internas que sostuvimos los mexicanos duraron tres lustros desde la consumación de la independencia nacional, y el sistema monárquico y el federal los sustituimos por un sistema centralista. Este fue el torpe pretexto de los colonos para hacernos la guerra separatista, ellos que habían jurado tres veces observar la doctrina y el ritual de la Iglesia Católica, apostólica, romana.

Pero, en 1836, disgustados los colonos texanos por ese régimen centralista que nos dimos, se levantaron en armas contra nuestro país [...] Después de varios meses de lucha militar contra los sublevados, acabó cediendo Texas con su mera firma, pero sin la aprobación de nuestro senado, institución que le habría dado legitimidad a la conducta antipatriótica de [Antonio López de] Santa Anna [1794-1876] ${ }^{19}$.

19 NEBEL, Carl e ITURRIAGA SAUCO, José E. (2006), op. cit., pp. 3 y 4 . He querido dejar el espaciado entre párrafos para hacer notar la manera original de la edición del cuadernillo, buscando a su vez enlazar 
La Guerra... es el atisbo de un viaje lúdico por el cerco nacional que el autor construye. En suma el álbum de Nebel es de positivo interés "[...] [ya que] están presentados con dignidad y sentido estético, de manera que deben haber sido muy novedosos para sus contemporáneos. Hoy día esas láminas tienen para nosotros, además de su valor documental y artístico, un gran encanto, pues evocan tiempos idos" ${ }^{20}$. El discurso, inmerso en un lenguaje característico del México decimonónico, es un leve movimiento cadencioso para enamorar a la vista que se ahoga en las aguas del mito nacional. Las litografías son la recreación de una invasión por "Unas cuantas docenas de colonos ilegales [...] [que] al saber que se habían roto las hostilidades en el Río Grande, izó la bandera de las barras y las estrellas en Monterrey, y declaró [imponiéndose] que California formaba parte de los Estados Unidos"21. Las imágenes se encuentran en el México pintoresco, a medio camino entre lo bello y lo sublime, entre la sensación de armonía y lo sobrecogedor; entre la paradoja de ser forjadores de una tradición, con éxito en los siglos XVIII y XIX, y su poca difusión, conocimiento, estudio ${ }^{22}$.

Es notorio el trabajo de dibujo por los detalles en las líneas, por las formas en las cuales se predice hallar los contorneados símbolos; para el romántico este detalle podía olerse, sentirse, en cada hoja. De los acabados al momento de grabar, litografiar, imprimir e iluminar, además de asentar que el encargo es técnicamente bien zanjado, están equilibrados, con las texturas que se presienten por uno u otro lado de las obras, con los brillos provocados, con los temas anunciando los tres planos y los ejes enmarcados o al centro. Es regular que los tonos azules, las escalas en café, verde, blanco dominen, aunque si "se observan los grabados con atención, se verá que [se] imprimió los elementos esenciales de la escena solo en dos colores -negro y un sepia grisáceo-, y que [se] manipuló con gran cuidado y delicadeza el negro para hacerlo aparecer en distintas tonalidades, de oscuras a claras" 23 . Para los detalles en las impresiones, en picoteo sobre la plancha, la fuerza del carácter o el cerco de los tiempos, se debe estancar la vista, moverla a pausas, desear hallar detalles que maravillen o expliquen ese discurso interno. En general, más allá de las batallas, más allá de los soldados en formación o en combate; más allá de los humos por las armas y quemazones, encontramos el México maravilloso. Las litografías de Nebel portan, con claridad, dos planos. El primero, la guerra y un dibujo exquisito. El segundo, el país mágico. Sobre este, quizá es lo que el autor recordó mejor con sus apuntes, fuentes y amigos.

Cuatro apostillas. Primero, Nebel realizó sus álbumes fuera de México porque su recepción estaba prevista para enamorar la vista de norteamericanos y europeos. Segundo, a pesar de que en el país existían prensas y/o talleres litográficos las referencias aducen a que era un arte en ciernes que no contaba ni con el personal, ni con el equipo,

\footnotetext{
todos los lenguajes estético-visuales del texto. Además, los aportes de las fechas y más que aparecen entre paréntesis "[ ]" fueron realizados por mí con la idea de situar cronológicamente los personajes, los actos.

20 FERNÁNDEZ, Justino (1967), op. cit., p. 34.

21 NEBEL, Carl e ITURRIAGA SAUCO, José E. (2006), op. cit., p. 14. Las cursivas son originales del texto.

22 DENER, Pablo, "El México pintoresco", en Artes de México, no 80, 2006, pp. 35-36.

23 TYLER, Ron, "Un gran libro estadounidense: The War between the United States and Mexico [sic], Illustrated", en Artes de México, nº 80, 2006, p. 55.
} 
ni con el material que asentaban las exigencias. Tercero, la información apunta a que el crecimiento del arte litográfico en el país se abrió paso en el segundo tercio del siglo XIX luego de Claudio Linati (Parma; 1790-1823), como resultado de una evolución y manejo de la técnica y los costos. Cuarto, referenciar el impacto de la obra en palabras del autor:

Al desembarcar en Nueva York, [a mediados del siglo XIX] Kendall se dirigió primero a Harper \& Brothers, editores de su Narrative of the Texan Santa Fe Expedition, para organizar la distribución de su libro, pero negoció un acuerdo más favorable con D. Appletaon \& Company. Entonces marchó a Nueva Orleans, donde mostró un ejemplar de la obra a sus colegas, organizó la venta a lo largo del río Mississippi, se tomó un respiro para compartir su entusiasmo con su hermana -"Todo mundo habla aquí en la forma más elogiosa de mi libro ilustrado. Sé que tendrá éxito"-, y regresó a Inglaterra. Ahí contrató al artista George Frederick Rosenberg para que coloreara 50 juegos de las doce escenas de batallas "tan bien, en todos sentidos, como los modelos que se le han dado", a tres chelines por grabado ${ }^{24}$.

La correspondencia imagen-palabra en La Guerra entre los Estados Unidos y México, editada por el Museo Soumaya, ofrece varias posibilidades de estudio. Sugiero un par de ideas para concluir. Primero, la obra ha sido armada en/por dos tiempos "redaccionales"; tomando las litografías de Carl Nebel y el escrito de José Ezequiel Iturriaga Sauco se formó una edición completa. Apropiando elementos de la crítica textual, el álbum es auténtico; respeta el terminado "genuino" y "fidedigno" deseado-cuidado por el artista. A su vez, las anotaciones, hechas con la distancia del tiempo, la reflexión de los acontecimientos y la curaduría de las imágenes, también representan un trabajo primigenio del escritor. En todo caso, vemos la representación de dos "versiones originales" que mantienen lazos comunicantes, sobre todo porque el texto del mexicano habrá de aparecer después, -quizá- con la intención de darle mayor soporte expresivo a las pinturas del alemán y/o explicar o a aleccionar con disquisiciones, claras y breves de/a cada una de las litografías, sobre todo en su papel histórico, más que estético ${ }^{25}$.

Segundo, el tema de la confrontación de las artes se vuelve un problema determinante en/para la estética, con el necesario planteamiento de resolución. En un sentido, el lenguaje pictórico y el lenguaje literario mantienen las mismas complicaciones, solo que sus maneras expresivas distan.

Una pincelada cualquiera es una opinión, ya que el pintor la aplica porque piensa que determinado color, en determinado lugar, aplicado de tal modo, es conveniente para lograr la perfecta consecución del cuadro. Y ello, motivado por cuanto sabe de su arte.

24 Artes de México, no 80 (número dedicado a Carl Nebel, pintor viajero del siglo XIX y coordinado por Arturo Aguilar), 2006, p. 52.

25 Para las terminología referente a la "crítica textual", tomé como referencia el artículo de PÉREZ MARTÍNEZ, Herón, “¿Cuál es el texto auténtico de la "Historia Verdadera”?”, en Relaciones, vol. XII, n 48, otoño de 1991, p. 84, nota. 1. La crítica textual tiene como objetivo recuperar el texto resultante de la actividad "redaccional" de un autor; establecer el texto originario, descubrir sus redacciones, la primera y la última. No es la búsqueda originaria, sino la más completa y definida. 
Pero huelga subrayar que el pintor puede ser completamente incapaz de explicarlo verbalmente, lo cual nada importa ${ }^{26}$.

A pesar de que los objetivos naturales de las litografías y del texto difieren, en su conjunto, como libro ilustrado discurren otro discurso. Las impresiones se realizaron para adular miradas estadounidenses, y de paso constituir simbólicamente la memoria gráfica de la primera guerra norteamericana fuera de sus fronteras ${ }^{27}$. El escrito fue pensado para revelar el evento histórico y/o referenciar cada una de las imágenes, a pesar de la carga de adjetivos nacionalistas que aprovisionan de una lectura no muy objetiva, con un autor balanceando sus considerandos para el lado mexicano. Las creaciones de Nebel y de Sauco forman una tercera obra armada aparte, distinta a las neoyorquina y parisiense. Como libro ilustrado, su lectura es más compleja porque su lenguaje juega con idiomas desconocidos, más no irreconciliables. Pintura y literatura, aquí, se conjugan para lograr un mismo fin. Su axioma íntimo les define a partir de las ordenanzas internas de jerarquías; por sus morfologías y normas constitutivas; en los nexos de las diversidades lingüísticas y, hasta, de sus fisiologías y anatomías que, englobadas, recrean un mudo, su mundo, particular. Nutre.

Esta telaraña, que arma La guerra entre los Estados Unidos y México, tiene su raíz en el elemento estético fundamental de crear impresiones al que ve-lee. Produce efectos sensibles para dar paso a otros, como el interés por la historia o los lugares de las batallas o las pericias de confección. Es un ejercicio de la toma del poder a través de las imágenes y las palabras vestidas con una retórica propia y consolidada con sus tácticas que, al final, son montajes estéticos. Los colores, los adjetivos, las figuras, los nombres, los edificios, las referencias; todo es una poderosa producción estética legítima, producida desde sus mediaciones autónomas, productora de significados sensibles. Descifrar los códigos y los subcódigos producidos, recrear el efecto de verdad o fascinar en grados personalísimos, es la intención estética de todo libro ilustrado.

Si bien, todo arte se nutre de su tiempo expresado en la inimitable reacción personal del artista, presente en los modos de pensar, de vivir y de sentir su época. La interpretación de la realidad, la actitud frente a la vida, los ideales, las tradiciones, las esperanzas y las luchas de una etapa histórica ${ }^{28}$ son posibles desentrañarse siendo fiel al espíritu del presente, el cual, además de profundizar, extiende la vida de la obra. La Guerra... es una saga donde se fusionan un par de agudezas originales para lograr una narración terminada, coherente y cerrada. Es la conquista, a su vez, de tonos irrepetibles e imposibles de modificar. Más allá de los elementos integrantes de la época y de la voluntad, consciente o no, de los creadores, para el caso de este libro ilustrado lo importante emerge en la soberana vitalidad artística sobre el actuar histórico de la epopeya, válido o no, para llevarnos a la conquista del objeto inmediato.

26 SOURIAU, Étienne, "El arte y las artes", en La Correspondencia de las artes, México, FCE, Breviarios, p. 35 .

27 Puede anotarse que la constitución de Estados Unidos de Norteamérica está fechada el 4 de julio de 1776 con la emisión de su Declaración de Independencia.

28 ECO, Umberto, La definición del arte, traducción R. de la Iglesia, Barcelona, Ediciones Destino, 2005, a su vez citado de Arte e letteratura nell'URSS del informe de Fadeev, Milano, 1950, y de Historia social del arte de Arnold Hauser, Madrid, 1962, 2 vols. 